\title{
Prevalence of under Nutrition and Associated Factors among Khat Chewers in Khat Chewing Shops at Gulalle Sub City, Addis Ababa, Ethiopia
}

\author{
Tesfaye Girma Legesse ${ }^{1, *}$ and Debela Gemeda Bedane ${ }^{2}$
}

\author{
${ }^{1}$ Department of Nutrition, Saint Paul's Hospital Millennium Medical College, Addis Ababa, Ethiopia \\ ${ }^{2}$ Department of Pharmacology, Saint Paul's Hospital Millennium Medical College, Addis Ababa, Ethiopia
}

\begin{abstract}
There is studies limitation regarding the effect of khat chewing on nutritional status. Community based comparative cross-sectional study had been conducted from March to June, 2015; with cluster sampling and systematic random sampling techniques for khat chewers and non-khat chewers respectively. The data was collected by using interview administered questionnaire, observation and weight scale measurement among 504 study participants. The study revealed that from entire khat chewers $52(20.5 \%)$ of them and of non-khat chewers $34(13.5 \%)$ of them were underweight. Khat chewers were 2.102 times more likely underweight compared to those non-khat chewers. khat chewers who had meal twice per day were 2.856 time more likely underweight. Khat chewers who used animal and animal products as their main meal component daily were 0.413 times less likely to be underweight; Whereas the odds of underweight was $26 \%$ times less likely among khat users who intake two liters of fluid per chewing session. In other case, those who chewed khat for 2-3 hours per session were 0.231 times less likely to be underweight. Under nutrition is a public nutritional status problem in which khat chewers are more affected. Khat chewing conditions and meal conditions including amount of fluid consumed per chewing session are factors that affect the nutritional status of the khat chewers. Minimizing amount of khat consumed per session, shortening of khat chewing session length and increasing amount of fluid intake more than two liters per chewing session and nutritional management with nutritionist advices are important points.
\end{abstract}

Keywords: Khat, under nutrition, khat chewers, non-khat chewers, Gulelle sub-city.

\section{INTRODUCTION}

Khat (Catha edulis) is an evergreen plant [1]. It is harvested throughout the year and it grows at high altitudes of 1500-2500 meters mainly in countries bordering the Red Sea and along the east coast of Africa including Ethiopia, Kenya, Yemen, Somalia, Sudan, Madagascar and South Africa [2, 3]. Khat is an addictive stimulant and highly prevalent drug among individuals $[4,5]$. Stimulation is commonly obtained by chewing the leaves privately or in small social gatherings by different sections of the community [1]. The practice of khat chewing dates back thousands of years in eastern Africa and the Arabian [1]. Ethiopia is thought to be the country of origin of khat use [2]. Khat is usually chewed in prolonged sessions, producing mild psycho-stimulant effects such as increased energy, reduce fatigue, increase performance, increase alertness and wakeful $[6,7]$.

Though people are chewing khat for multiple reasons, it has huge public health impact on mental, physical and social well-being. It also leads to problems like chronic gastritis, upper gastrointestinal malignancy

${ }^{*}$ Address correspondence to this author at the Department of Nutrition, Saint Paul's Hospital Millennium Medical College, Addis Ababa, Ethiopia;

Tel: + 251 913227913; E-mail: girmanet12@gmail.com including weight loss [8], delaying of gastric emptying of semi-solid food, dental caries, gingival bleeding and difficulty in mouth-opening and swallowing solid food $[4,9]$. The habit of khat chewing is believed to affect a large segment of the Ethiopian population, especially the productive age group i.e., it has negative impact on health, socioeconomic and political matters [10]. According to the report in 2011 on the health risks of khat and influences it has on integration issues by using qualitative, snowball sampling technique, in Stockholm and Västerås cities it found that loss of appetite, While the perception of the participants towards long-term use of khat is associated with anorexia that leads users of khat to malnutrition [11]. In other case, gastritis, constipation, loss of appetite and malnutrition are among the adverse effects of khat use as to a review on hazards of khat chewing in 2013 [12].

There are studies which show prevalence of khat chewing, economical effect and health effect of khat chewing based on self reporting of khat chewer and there are recommendations on improving of negative effect of khat chewing by many researchers. But there is limitation of studies related to nutritional status assessments specially using anthropometries and associated factors. So the present study incorporates anthropometry measurement values to increase

(c) 2016 Lifescience Global 
knowledge on effect of khat chewing on nutritional status of khat chewers.

\section{METHOD AND MATERIALS}

\subsection{Study Design, Aim, Area and Period}

Community based comparative cross-sectional study had been conducted on the prevalence of undernutrition and associated factors among khat chewers in khat chewing shops at Gulalle sub city, Addis Ababa, Ethiopia from March to June, 2015.

\subsection{Study Participants}

All adults who chewed khat for more than six months and chewing khat in the khat chewing houses during the study time. All non-khat chewing adults living in houses around the khat chewing shops during the study period were participated. Severely sick and pregnant women were excluded.

\subsection{Sample Size Determination}

Using the prevalence of underweight $50 \%$ for khat chewers \& $31.8 \%$ [13] for non-khat chewers, with $95 \%$ certainty \& $80 \%$ power of detection, a total of 506 participants were obtained by applying two population proportion formula using EPI.INFO version 7. Then they enrolled to the study with the ratio of non-khat users to khat users 1:1.

\subsection{Sampling Procedure}

Three woredas had been selected by lottery methods among the ten woredas found in Gulelle sub city. Then the khat chewing houses had been selected by lottery method from each the selected woredas. Cluster sampling techniques and systematic random sampling techniques had been used for khat chewing groups and non-khat chewers respectively.

\subsection{Operational Definitions}

Under Nutrition - in this study it is the state in which the body mass index (BMI) measurement value is less than 18.5 .

Substance - alcohol that is used post khat chewing for calming down the stimulation effect of khat

Chronic Khat Chewers- according to this study those who used khat for more than five years and chewed for more than four hours and over $100 \mathrm{~g}$ of khat per session.

\subsection{Data Collection Methods}

Structured and semi-structured interview administered questionnaire, observation and anthropometry measurement by trained data collector nurses had been used. All questioners were formulated based on the literature review done.

\subsection{Data Analysis}

Coded data is loaded to EPI-INFO version 7 after a data entry template was prepared. Then the data is transferred to SPSS version $\mathbf{2 0 . 0}$ for analysis. The data had been analyzed by using bivariate logistic regression. Selection and filtration of the comparative groups were done by splitting into khat chewer and non-khat chewer participants alternatively. Crude odds ratio (COR) and adjusted odds ratio (AOR) with $95 \% \mathrm{CI}$ had been calculated to determine the strength of association between dependent and independent variables. P-value less than 0.05 had been used to see the significance; whereas variables with $p$-value less or equal to 0.05 had been enrolled to multivariate analysis.

\subsection{Ethical Consideration}

Ethical clearance had been obtained from Ethical review committee of university of Gondar. In order to obtain permission letter we have contacted Gulelle sub city administrative office. The participants had been informed about the purpose of the study and the importance of their participation. Privacy and confidentiality of the information given by each respondent is kept properly and number code used otherwise name had not been recorded.

\section{RESULT}

\subsection{Socio Demographic Characteristics of the Study Participants}

Among the total 506 participants planned to be included in the study 504 were participated with responding rate of $99.6 \%$ in which $239(47.42 \%)$ of them were male and $14(2.77 \%)$ of them were female khat chewers. While $226(44.84 \%)$ and $25(4.96 \%)$ of them were male and female non-khat chewers respectively.

The study identified that of the total participants $86(17.1 \%)$ of them were underweight. Whereas of the total khat chewers $52(20.6 \%)$ of them and of non-khat chewers $34(13.5 \%)$ of them were underweight. In other case $49(19.4 \%)$ and $3(1.2 \%)$ of khat chewers were 
Table 1: Distribution of under Nutritional Status of the Study Population with it's Affecting Factors among Khat Chewers in Khat Chewing Shops at Gulalle Sub City, Addis Ababa, Ethiopia, 2015

\begin{tabular}{|c|c|c|c|c|}
\hline \multirow{2}{*}{ Khat use } & \multirow{2}{*}{ Variables } & \multicolumn{3}{|c|}{ Underweight } \\
\hline & & Yes $\mathrm{N}(\%)$ & No $N(\%)$ & Total N (\%) \\
\hline \multirow[t]{4}{*}{ Yes } & \multicolumn{4}{|l|}{ Alcohol use } \\
\hline & No & $35(13.8)$ & 106(41.9) & $141(55.7)$ \\
\hline & Yes & $17(6.7)$ & $95(37.5)$ & 112(44.3) \\
\hline & Total & $52(20.6)$ & $201(79.4)$ & $253(100)$ \\
\hline \multirow{2}{*}{ No } & Yes & $8(3.2)$ & $94(37.5)$ & 102(40.6) \\
\hline & Total & $34(13.5)$ & $217(86.5)$ & $251(100)$ \\
\hline \multirow[t]{3}{*}{ Yes } & \multicolumn{4}{|c|}{ Additional substance use frequency per week } \\
\hline & Less than 3 days & $7(3.4)$ & $30(14.5)$ & $37(17.9)$ \\
\hline & Total & $45(21.7)$ & $162(78.3)$ & $207(100)$ \\
\hline \multirow[t]{4}{*}{ No } & Less than 3 days & $5(4.7)$ & $57(53.3)$ & $62(57.9)$ \\
\hline & $\geq 3$ days & $3(2.8)$ & 19(17.8) & $22(20.6)$ \\
\hline & Daily & $3(2.8)$ & $20(18.7)$ & $23(21.5)$ \\
\hline & Total & $11(10.3)$ & $96(89.7)$ & $107(100)$ \\
\hline \multirow[t]{3}{*}{ Yes } & \multicolumn{4}{|c|}{ Length of additional substance use in year } \\
\hline & $<3$ years & $8(4.1)$ & $21(10.7)$ & $29(14.7)$ \\
\hline & $3-5$ years & $14(7.1)$ & $26(13.2)$ & $40(20.3)$ \\
\hline \multirow{2}{*}{ No } & $>10$ years & $3(2.8)$ & $27(25.5)$ & $30(28.3)$ \\
\hline & Total & $11(10.4)$ & $95(89.6)$ & $106(100)$ \\
\hline \multirow[t]{6}{*}{ Yes } & \multicolumn{4}{|l|}{ Meal frequency } \\
\hline & Once & $3(1.2)$ & $6(2.4)$ & $9(3.6)$ \\
\hline & Twice & $20(7.9)$ & $55(21.7)$ & $75(29.6)$ \\
\hline & Three & $25(9.9)$ & $117(46.2)$ & $142(56.0)$ \\
\hline & More than 3 times & $4(1.6)$ & 23(9.1) & $27(10.7)$ \\
\hline & Total & $52(20.6)$ & $201(79.4)$ & $253(100)$ \\
\hline \multirow[t]{5}{*}{ No } & Once & $1(0.4)$ & $4(1.6)$ & $5(2.0)$ \\
\hline & Twice & $6(2.4)$ & $32(12.7)$ & $38(15.1)$ \\
\hline & Three & $27(10.8)$ & $171(68.0)$ & 198(78.9) \\
\hline & More than 3 times & $0(0.0)$ & $10(4.0)$ & $10(4.0)$ \\
\hline & Total & $34(13.5)$ & $217(86.5)$ & $251(100)$ \\
\hline
\end{tabular}


(Table 1). Continued

\begin{tabular}{|c|c|c|c|c|}
\hline Khat use & Variables & \multicolumn{3}{|c|}{ Underweight } \\
\hline \multirow[t]{5}{*}{ Yes } & \multicolumn{4}{|c|}{ Interval of animal and animal products gaining } \\
\hline & Twice per week & 22(9.3) & $88(37.1)$ & $110(46.4)$ \\
\hline & Once per week & $11(4.7)$ & $28(11.9)$ & $39(16.6)$ \\
\hline & $>15$ days & $3(1.3)$ & $15(6.1)$ & 18(9.4) \\
\hline & Total & $52(20.6)$ & $201(79.4)$ & $253(100)$ \\
\hline \multirow[t]{4}{*}{ No } & Twice per week & $12(5.1)$ & $87(37.2)$ & $99(42.3)$ \\
\hline & Once per week & $13(5.6)$ & $59(25.2)$ & $72(30.8)$ \\
\hline & $>15$ days & $3(1.3)$ & $10(4.3)$ & $13(5.6)$ \\
\hline & Total & $34(13.5)$ & $217(86.5)$ & $251(100)$ \\
\hline
\end{tabular}

male and female underweight respectively. While $31(12.4 \%)$ and $3(1.2 \%)$ of non- khat chewer were male and female underweight respectively. Even though the probability of being underweight was more observed among khat chewers in all age classes, the most probability of being underweight was observed among the age class of $18-30$ years showing that $35(13.8 \%)$ of them were khat chewers and $27(10.8 \%)$ of them were non-khat chewers.

Of the total khat chewers $38(15 \%)$ of them and of non-khat chewers $26(10.4 \%)$ of them were underweight orthodox Christianity followers; followed by Muslim, protestant and catholic religion followers orderly. Thirty five $(6.94 \%)$ of the unmarried and $16(3.17 \%)$ of the married khat chewers were underweight; whereas $27(5.35 \%)$ of the unmarried and $7(1.38 \%)$ of the married non-khat chewers were underweight. The study also revealed that of the entire khat chewers who work for $12-16$ hours per day $18(7.1 \%)$ of them were underweight; whereas of entire non-khat users who work for $12-16$ hours per day $6(2.4 \%)$ of them were underweight.

\subsection{Distribution of under Nutritional Status of the Study Populations' with it's Affecting Factors}

In case of khat chewers, as frequency of substance use increased the chance of being underweight was also increased; but no differences observed for nonkhat chewers. The risk of being underweight was more observed among khat chewers who used additional substance for more than 3 years and less than ten years. But in case of non-khat chewer substance users who took the substance for less than 3 years and more than ten years were more at risk to be underweight.

Though both khat chewers and non-khat chewers who had meal more than three times per day were had the least opportunity of being underweight, the chance of being underweight was higher in entire the khat users. The study identified that for both khat chewers and non-khat chewers being underweight was highest among plant and plant product meal users as their main daily meal component; but it was higher among khat-chewers than non-khat chewer. Of all khat chewers $37(14.7 \%), 12(4.7 \%)$ and $3(1.2 \%)$ of them were underweight plant and plant products, animal and animal products and mixed diet users as their main daily meal component respectively; whereas of all nonkhat chewers $24(9.6 \%), 5(2 \%)$ and $4(1.6 \%)$ of them were underweight plant and plant products, animal and animal products and mixed diet users as their main daily meal respectively. Even though it was less among khat chewers, as fruit and vegetable intake frequency increased per week, the probability of getting underweight was decreased in both khat chewers and non-khat chewers. Though the risk of underweight was decreased as animal and animal product meal using frequency is increased, the risk was higher among khat-chewers than non-khat chewers. Out of the anorexic khat chewers $17(6.7 \%)$ of them and of the anorexic non-khat chewers $10(4.0 \%)$ of them were observed to be under weight (Table 1). 
3.3. Prevalence of under Nutrition with Specific Socio-Demographic Characteristics of the Khat Chewers

As khat chewing starting age increased the possibility of being underweight was observed to be decreased; in which the chance of being underweight was highest among those who started khat chewing before $21^{\text {st }}$ of their age. Those who chewed khat for a length of more than 3 years to less than 10 years were mostly affected to be underweight. Losing of weight was increased as the frequency of khat chewing increased; while daily khat chewers were more affected. In other case, khat chewers who used about $100 \mathrm{gm}-150 \mathrm{gm}$ of khat per khat chewing session were the most affected group to be underweight than other

Table 2: Prevalence of under Nutrition among Khat Chewers with Specific Socio-Demographic Characteristics of Khat Chewers in Khat Chewing Shops at Gulalle Sub City, Addis Ababa, Ethiopia, 2015

\begin{tabular}{|c|c|c|c|}
\hline \multirow{2}{*}{ Khat chewing starting age } & \multicolumn{2}{|c|}{ Underweight } & \multirow{2}{*}{ Total N (\%) } \\
\hline & Yes N (\%) & No $N(\%)$ & \\
\hline$\leq 20$ years & $26(10.3)$ & $73(29.0)$ & $99(39.3)$ \\
\hline $21-25$ years & $21(8.3)$ & $78(31.0)$ & $99(39.3)$ \\
\hline $26-30$ years & $5(2.0)$ & $45(17.4)$ & $50(19.4)$ \\
\hline$\geq 31$ years & $0(0.0)$ & $5(2.0)$ & $5(2.0)$ \\
\hline Total & $52(20.6)$ & $201(79.4)$ & $253(100)$ \\
\hline \multicolumn{4}{|l|}{ Length of khat chewing in years } \\
\hline$<3$ years & $7(2.8)$ & $26(10.2)$ & $33(13.0)$ \\
\hline $3-5$ years & $15(6.0)$ & $35(13.9)$ & $50(19.8)$ \\
\hline$>5-10$ years & $16(6.3)$ & $55(21.8)$ & $71(28.2)$ \\
\hline$>10-15$ years & $11(4.4)$ & $75(29.9)$ & $86(34.2)$ \\
\hline$>15 y e a r s$ & $3(1.2)$ & $10(4.0)$ & $13(5.2)$ \\
\hline Total & $52(20.6)$ & $201(79.4)$ & $253(100)$ \\
\hline \multicolumn{4}{|l|}{ Frequency of khat chewing per week } \\
\hline Less than 3 time & $11(4.3)$ & $45(17.4)$ & $56(21.9)$ \\
\hline Greater than 3 time & $18(7.1)$ & $52(20.6)$ & $70(27.7)$ \\
\hline Daily & $23(9.2)$ & 104(41.4) & $127(50.6)$ \\
\hline Total & $52(20.6)$ & $201(79.4)$ & $253(100)$ \\
\hline \multicolumn{4}{|l|}{ Amount of khat used per session } \\
\hline $25-50 \mathrm{gm}$ & $15(6.0)$ & $50(20.1)$ & $65(26.1)$ \\
\hline $75-100 \mathrm{gm}$ & 23(9.2) & $99(39.8)$ & $122(49.0)$ \\
\hline$>100 \mathrm{gm}-150 \mathrm{gm}$ & $9(3.6)$ & $25(10.0)$ & $34(13.7)$ \\
\hline$>150 \mathrm{gm}$ & $4(1.6)$ & $24(9.6)$ & $28(11.2)$ \\
\hline Total & $52(20.6)$ & $201(79.4)$ & $253(100)$ \\
\hline \multicolumn{4}{|l|}{ Length of khat chewing session } \\
\hline$<2$ hours & $5(2.0)$ & $18(7.2)$ & $23(9.2)$ \\
\hline $2-3$ hours & $8(3.2)$ & $41(16.3)$ & $49(19.5)$ \\
\hline 4-5 hours & $23(9.2)$ & $91(36.3)$ & $114(45.4)$ \\
\hline$\geq 6$ hours & $16(6.4)$ & $49(19.5)$ & $65(25.9)$ \\
\hline Total & $52(20.6)$ & $201(79.4)$ & $253(100)$ \\
\hline \multicolumn{4}{|l|}{ Khat chewers' feeding habit } \\
\hline Feeding before chewing & $36(14.2)$ & $146(57.7)$ & $182(71.9)$ \\
\hline Feeding after chewing & $4(1.6)$ & $19(7.5)$ & $23(9.1)$ \\
\hline Feeding when get hungriness & $12(4.7)$ & $25(10)$ & $37(14.7)$ \\
\hline Lack of appetite & $0(0.0)$ & $11(4.3)$ & $11(4.3)$ \\
\hline Total & $52(20.6)$ & $201(79.4)$ & $253(100)$ \\
\hline
\end{tabular}


groups who chewed different amount of khat per session. As the length of khat chewing session increased the chance of being underweight was also increased. Khat chewers who had practice of feeding before khat chewing were the most at risk group to be underweight followed by khat chewers who had practice of feeding when felt hunger and who had practice of feeding after khat chewing session sequentially (from Table 2 ).

\subsection{Factors Significantly Associated with Nutritional Status of the Khat Chewers}

The current study identified that Khat chewers were more likely to be under nutrition compared to nonchewers. The study found that khat chewing patterns, amount of fluid intake per chewing session, additional substance using frequency per week and meal patterns were factors significantly associated with khat chewing to be under nutrition. The detail had been presented in Table 3.

\subsection{Factors Significantly Associated With Nutritional Status of the Non-Khat Chewers}

Unlike khat chewers, the type of main meal component had no effect on weight of non-khat chewers, except animal and animal products users that had 0.202 times less like to be underweight compared with mixed type of food users at $(A O R=.202,95 \% \mathrm{Cl}$ [0.044-0.938]. Non-khat users who had a chance of getting animal and animal product meals twice per week were 0.038 times less likely underweight taking those who had this meal by the interval of Longer than 15 days $(A O R=0.038,95 \% \mathrm{Cl}$ [0.002-0.834]. In other way, non-khat users who had not developed anorexia were 0.124 time less likely to be underweight (AOR= $0.124,95 \% \mathrm{Cl}[0.017-0.909])$.

\subsection{Observational Findings}

It is observed that as almost all khat chewers were look like thin or wasted and have had dry lips on observation.

\section{DISCUSSION}

The study revealed that from all khat chewers $52(20.60 \%)$ of them and of non-khat chewers $34(13.5 \%)$ of them were underweight. This indicates that khat chewing had independent effect on nutritional status of the khat chewers.

According to the report in 2014 on khat use prevalence, causes and its effect on mental health,
Bahirdar, North West Ethiopia using causal comparative study design, with quantitative and qualitative found that appetite loss, insomnia and feeling of being busy were among the effect of khat use [5]. This idea is supported by the current study also. This might be because of similarity of the study design used, live style of the two cities' population and study time proximity.

Khat is usually chewed in prolonged sessions, producing mild psycho-stimulant effects such as increased energy, reduce fatigue, increase performance, increase alertness and wakeful $[6,7]$. The Current study also identified that khat is mostly used in prolonged sessions. This might be because of the similarity of peak time of khat chewing session in which stimulation obtained.

According to the study report on nutritional status and associated factors among school adolescent in Chiro town, west Hararge, Ethiopia using Crosssectional quantitative study design in 2013 khat chewers were found to be two times more likely to become underweight than who don't chew khat [AOR=2.45 Cl=1.07, 5.64], [16]. Which is similar with the current study that identified khat chewers become 2.102 times more likely to be underweight compared with those non-chewers (AOR $=2.102$ [1.054-4.110]). Even though study participant are different, the result might be due to common characteristic of style of khat chewing and similar study design used.

The current study revealed that $20.60 \%$ of the khat chewer participants are underweight; of which $19.4 \%$ of them were male; which is almost the same to the study done on the effect of Khat (Catha edulis) chewing on blood pressure among male adult Chewers, in Bahir Dar, North west Ethiopia in 2014 by using community based cross-sectional study among khat chewers of Bahir Dar city which identified that about $19.9 \%$ were underweight [15]. This might show khat chewing conditions are almost similar everywhere. In addition, both studies were conducted using similar study design and within very proximate study time.

The study done on nutritional status and associated factors among school adolescent in Chiro town, west Hararge, Ethiopia using Cross-sectional quantitative study design in 2013 found that khat chewers who got two or less meal per day $15(26.3 \%)$ were underweight and consumers of low diet diversity found to be more underweight than high diet diversity consumer $(27.9 \%$ vs $23 \%$ ) [16]. similarly the current study identified that as the main staple especially animal and animal product and frequency of meal were factor of being 
Table 3: Factors Significantly Associated with under Nutritional Status of Khat Chewers among Khat Chewers in Khat Chewing Shops at Gulalle Sub City, Addis Ababa, Ethiopia, 2015

\begin{tabular}{|c|c|c|c|c|c|}
\hline \multirow{2}{*}{ Variables } & \multicolumn{2}{|c|}{ Underweight } & \multicolumn{3}{|c|}{ 95\% Confidence Interval } \\
\hline & Yes & No & COR & AOR & P-value \\
\hline \multicolumn{6}{|l|}{ Khat Chewing } \\
\hline Yes & 52 & 201 & $1.651[1.457-3.102]$ & $2.102[1.054-4.110]$ & 0.022 \\
\hline No & 34 & 217 & 1.00 & 1.00 & \\
\hline \multicolumn{6}{|c|}{ Length of khat chewing in years } \\
\hline$<3$ years & 7 & 26 & $.896[1.210-4.438]$ & $.023[.003-0.741]$ & 0.032 \\
\hline $3-5$ years & 15 & 35 & $1.429[.379-6.757]$ & $.123[.006-2.451]$ & \\
\hline$>5-10$ years & 16 & 55 & $.970[.256-4.210]$ & $.140[.007-2.864]$ & \\
\hline$>10-15$ years & 11 & 75 & $.489[.168-2.992]$ & $.093[.006-1.524]$ & \\
\hline >15years & 3 & 10 & 1.00 & 1.00 & \\
\hline \multicolumn{6}{|c|}{ Amount of khat used per session } \\
\hline $25-50 \mathrm{gm}$ & 15 & 50 & $1.801[.599-6.845]$ & $4.601[0.981-23.213]$ & \\
\hline $75-100 \mathrm{gm}$ & 23 & 99 & $1.384[1.393-5.100]$ & $3.102[.821-27.204]$ & \\
\hline$>100 \mathrm{gm}-150 \mathrm{gm}$ & 9 & 25 & $2.160[1.281-9.713]$ & $2.031[1.023-18.124]$ & 0.034 \\
\hline$>150 \mathrm{gm}$ & 4 & 24 & 1.00 & 1.00 & \\
\hline \multicolumn{6}{|c|}{ Length of khat chewing session } \\
\hline$<2$ hours & 5 & 18 & $.794[.248-2.539]$ & $0.412[.078-1.263]$ & \\
\hline 2-3 hours & 8 & 41 & $.556[.201-.721]$ & $0.231[0.017-.902]$ & 0.046 \\
\hline $4-5$ hours & 23 & 91 & $.74[.359-1.527]$ & $1.064[.437-2.590]$ & \\
\hline$\geq 6$ hours & 16 & 49 & 1.00 & 1.00 & \\
\hline \multicolumn{6}{|c|}{ Amount of fluid intake per chewing session } \\
\hline$<1$ litter & 11 & 28 & $1.326[.277-2.545]$ & $2.032[.553-1.503]$ & \\
\hline Two litters & 14 & 100 & $0.472[.109-.853]$ & $0.260[.043-0.831]$ & 0.017 \\
\hline 3 litters & 19 & 46 & $1.390[.368-2.882]$ & $1.964[.734-7.363]$ & \\
\hline$>3$ litters & 8 & 27 & 1.00 & 1.00 & \\
\hline \multicolumn{6}{|c|}{ Additional substance frequency per week } \\
\hline Less than 3days & 5 & 57 & $.585[1.101-3.612]$ & $0.423[0.316-0.904]$ & 0.032 \\
\hline$\geq 3$ days & 3 & 19 & $1.060[.593-3.122]$ & $0.492[0.807-11.216]$ & \\
\hline Daily & 3 & 20 & 1.00 & 1.00 & \\
\hline \multicolumn{6}{|l|}{ Meal frequency } \\
\hline Once & 3 & 6 & $2.875[.575-27.82]$ & $1.654[.056-24.542]$ & \\
\hline Twice & 20 & 55 & $2.090[1.539-6.137]$ & $2.856[1.052-17.851]$ & 0.038 \\
\hline Three & 25 & 117 & $1.155[.357-3.734]$ & $1.601[0.638-9.431]$ & \\
\hline more than 3times & 4 & 23 & 1.00 & 1.00 & \\
\hline \multicolumn{6}{|c|}{ Interval of animal and animal products gaining } \\
\hline Twice per week & 20 & 80 & $.417[0.163-3.063]$ & $2.213[0.567-7.267]$ & \\
\hline Once per week & 11 & 31 & $.591[.190-3.971]$ & $0.423[0.054-6.424]$ & \\
\hline Daily & 14 & 65 & $.359[0.124-0.982]$ & $0.413[0.052-0.828]$ & 0.044 \\
\hline Every 15 days & 2 & 5 & $.667[.021-.879]$ & $0.632[.076-8.432]$ & \\
\hline$>15$ days & 3 & 5 & 1.00 & 1.00 & \\
\hline
\end{tabular}


underweight among khat chewers. Even though the study areas and population are different, the common effect observed might be due to the similar effect of meal frequency and diet diversity had independent on the nutritional status of the chewers. On top of that both studies were conducted using similar study design.

The habit of khat chewing is believed to affect a large segment of the Ethiopian population, especially the productive age group [10]. Similarly the current study also found that most of the khat chewers are in the productive age group. This might be due to the assumption of getting alertness, energy and concentration to accomplish their work and assumption of using khat as the means of enjoyment.

According to the report in 2011 on the health risks of khat and influences it has on integration issues [11] and a review in 2013 on hazards of khat chewing [12] found that as khat cause loss of appetite and malnutrition; According to a review done on the potential adverse effects of habitual use of Catha edulis (khat) at University of Sana'a, Department of Clinical Biochemistry, Faculty of Medicine and Health Sciences ,Republic of Yemen in 2005 it found that delay to intestinal absorption contributes to malnutrition of the khat users [17]. On top of these, other study in 2013 on khat chewing practice and its perceived health effects among communities of Dera Woreda, Amhara region, Ethiopia by using community-based cross-sectional quantitative and qualitative study design found that loss of appetite is among the adverse effect of khat chewing [2] which are similar with the current study finding. Even though the study areas and population are different the common effect had been observed due to the similar side effect of khat had independently on the nutritional status and related conditions of the chewers.

According to the report of the study done on Influence of Khat Chewing on Periodontal tissues and oral hygiene status in Yemenis among patients attending the outpatient dental clinics of the government dental college, Sana'a University, Yemen in 2010 using cross sectional study found that about $23 \%$ of chewers complained of difficulty in mouth opening, $10 \%$ of chewers had difficulty in swallowing solid food, and burning sensation in the soft tissues was also found in a higher proportion of khatchewers[14]. While the current study do not identified these problems which are directly or indirectly affect the nutritional status of the victim. This might be due to the study population differences.

According the study report on age-related factors influencing the occurrence of under nutrition in northeastern Ethiopia using community-based crosssectional study in Harbu Town, northeastern Ethiopia in 2013; prevalence of under nutrition was $31.8 \%$ among the community and $21.1 \%$ among adults [13].This is higher to the current study finding, which is $86(17.1 \%)$ of the total participants are identified to be underweight. This could be because of different study area and different study population in which the current study excluded children.

Khat chewers who took fluid about 6 glass of water per chewing sesion were 0.260 times less likely to be underweight at $(95 \% \mathrm{Cl}$, and $\mathrm{AOR}=0.260$ [0.0430.831 ] comparing to taking more than 9 glass of water per chewing session. This may be due to the water dilution effect and antioxidant effect that help in reduction of the chemical effect khat has.

According to the study in US in 2010 using cohort studies, women who consume alcohol at a small or moderate rate (up to $30 \mathrm{~g} /$ day) have a lower risk to gain weight and become obese than those who abstain from it [18]. Even though the study population is different the current study also supports the above finding indicating that using alcohol post the khat chewing session had preventive effect on being under nutrition. This is mostly because of the depression effect alcohol has by nature, might calm down the stimulation gain from khat chewing; which later help in preventing the side effect khat has on nutritional status of the khat chewers in addition to it's source of calorie.

\section{CONCLUSION}

The study identified that underweight is a public nutritional status problem in which khat chewers are more affected. Khat chewing patterns and meal patterns including amount of fluid consumed per chewing session are among the factors that affect the nutritional status of the khat chewers. Minimizing amount of khat per session, shorting of khat chewing session length and length of khat chewing years, increasing amount of fluid intake to more than two liters per chewing session, increasing the chance of animal and animal product meals obtaining based on the nutritionist advices are the core points. It is also identified that using substance (alcohol) after khat chewing session decreased the possibility of being underweight.

\section{RECOMMENDATIONS}

* Fat deposition status of the khat chewers and laboratory based nutritional effect of khat should 
be studied and the question does khat have the effect of treatment to obese should be answered.

* The side effect alcohol has on the health of the khat chewers should be identified before recommending it.

* Those khat users should use more than two liters of fluid per chewing session to prevent the side effect of khat chewing has on their nutritional status.

* khat users should increase using of animal and animal product meals frequency per week based on nutritionist advices; should take meal more than three times per day

* Decreasing amount of khat per session, session length to 2-3 hours and length of chewing years to less than 3 years

\section{ACKNOWLEDGEMENT}

We are very glad to present our acknowledgement to Gulelle sub-city woredas' administration offices for coordinating the study areas, we are interested to forward our deepest gratitude to those data collectors for their patience and honesties to collect qualified data and need to say thank you to all participants for their cooperation.

\section{REFFERENCES}

[1] Reda AA, Moges A, Biadgilign S. Wondmagegn. Prevalence and determinants of khat (catha edulis) chewing among high school students in eastern Ethiopia. PLoS ONE 2012; 7(3): 3-4.

http://dx.doi.org/10.1371/journal.pone.0033946

[2] Zeleke A, Awoke W, Gebeyehu E, Ambaw F. Khat chewing practice and its perceived health effects among communities of Dera Woreda, Amhara region, Ethiopia. Open Journal of Epidemiology 2013; 3(1): 163-7.

http://dx.doi.org/10.4236/ojepi.2013.34024

[3] MP RHCC. Khat (Qat): Assessment of Risk to the Individual and Communities in the UK. Advisory council on the misuse of drugs home office, 2 Marsham Street, London SW1P 4DF 2005; 19-22.
[4] Kebede Y. Cigarette smoking and Khat chewing among College students in North West Ethiopia. Ethiopia J Health Dev 2002; 16(1): 3-5. http://dx.doi.org/10.4314/ejhd.v16i1.9818

[5] Gebiresilus AG, Gebresilus BG, Yizengaw SS, Sewasew DT, Mengesha TZ. khat use prevalence, causes and its effect on mental health, Bahir-Dar,North West Ethiopia. European Scientific Journal 2014; 10(23).

[6] Douglas $\mathrm{H}$, Boyle M, Lintzeris $\mathrm{N}$. The health impacts of khat: a qualitative study among Somali-Australians. MJA 2011; 195(11/12): $667-8$

http://dx.doi.org/10.5694/mja11.10166

[7] Kassim S. an exploration of the association between khat chewing and health outcomes in UK-resident male Yemeni khat chewers. International Dental Journal 2010; 174-196.

[8] Dhaifalaha I, Šantavy J. khat habit and its health effect. A natural amphetamine. Macmillan Publishers Limited 2004; 148(1): 13.

[9] Walle M. Khat Chewing and Self Rated Oral Health Out Comes in Bahir Dar, North West Ethiopia. American Journal of Health 2014; 2(6): 346-347. http://dx.doi.org/10.11648/j.ajhr.20140206.14

[10] Kebede $Y$, et al. substance abuse for the Ethiopian health center team: Gondar University 2005: 9-17. www.cartercenter.org/resources/pdfs/health

[11] Yusuf B. The health risks of khat and influences it has on integration issues. Mälardalen University 2011; 49. www. diva-portal.se/smash/get/diva2:766652/FULLTEXT01.pdf

[12] Basker GV. A review on hazards of khat chewing. Int $J$ Pharm Pharm Sci 2013; 5(3): 1.

[13] Degarege A, Hailemeskel E, Erko B. Age-related factors influencing the occurrence of under nutrition in northeastern Ethiopia. BMC Public Health 2015; 15(108): 4-5.

[14] Abdulwahab I. Al-Kholani. Influence of khat chewing on periodontal tissues and oral hygiene status among Yemenis. Dent Res J (Isfahan) 2010; 7(1): 4.

[15] Birhane BW, Birhane MW. The Effect of Khat (Catha edulis) Chewing on Blood Pressure among Male Adult Chewers, Bahir Dar, North West Ethiopia. Science Journal of Public Health 2014; 2(5): 464-6. http://dx.doi.org/10.11648/j.sjph.20140205.23

[16] Damie TD, Wondafrash M, Nigussie A. Nutritional status and associated factors among school adolescent in Chiro town, west Hararge, Ethiopia. Ethiopian Journal of Health Sciences 2013; 5-17.

[17] Molham Al-Habori. The potential adverse effects of habitual use of Catha edulis (khat). Sana'a, Republic of Yemen. Ashley Publications www.ashley-pub.com 2005; 4.

[18] Wang L, Lee IM, Manson JE, Buring JE, Sesso HD. Alcohol consumption, weight gain, and risk of becoming overweight in middle-aged and older women.US national instuit of health. Arch Intern Med 2010; 170(5): 453-61. http://dx.doi.org/10.1001/archinternmed.2009.527 